\title{
Finite element checking of flange connection in integral hoisting of flare stack
}

\author{
Xuanyu Sheng ${ }^{1, a}$, Hongzhi Zhang ${ }^{2}$ and You Bao ${ }^{2}$ and Chen Ling ${ }^{3}$ \\ ${ }^{1}$ Department of Mechanical Engineering, Tsinghua University, Beijing, 100084, China \\ ${ }^{2}$ Daqing OilField Construction Group Co., Ltd. Installment Co., Beijing, 100044, China \\ ${ }^{3}$ Tianjin Research Institute for Advanced Equipment, Tsinghua University, Tianjin, 300300, China
}

\begin{abstract}
Segmentation hoisting is generally used for flare stack with flange connection structure. This paper presents a technical innovation of integral hoisting of flare stack with flange connection structure. In the paper, CATIA finite-element-analysis is used to build $100 \%$ model of flare stack and to simulate working condition in both horizontal and vertical limit states during integral hoisting of flare stack. Strength and stability of flare stack during hoisting is checked and calculated, dangerous points are found, measures of strengthening weak structure are proposed and references are provided for hoisting procedure design and formulation of hoisting plan.
\end{abstract}

Keywords: flange connection; flare stack; integral hoisting; CATIA finite-element-analysis; strengthen.

\section{Preface}

The flange connection structure of flare stack are generally hoisted by segmentation hoisting, but flare stack hoisting project in Zhongqiqianlin Station Risk Management Project is a winter construction project. During the construction, it's very cold, windy and snowy, this is extremely unfavorable environment for lifting construction, operation is very difficult. Segmentation hoisting work will cause high risk in climbing construction, high labor intensity;. In this regard, we boldly tries to propose a kind of integral hoisting method. By combination of each sides, we determine the reasonable reinforcement and the integral hoisting of the stack, this paper conduct check calculation and analysis for the whole flare stack hoisting process.

\section{Flare stack structure parameters}

In Zhongqiqianlin Station Risk Management Project, we need to install a three column flare for venting system. According to the drawings given by manufacturer, flare stack is 32 meters high, flare head is 3 meters high, total height is $35 \mathrm{~m}$, total weight is 16.3 tons. Stack body and the cylinder body are all steel pipe, connection between main material of stack and cylinder connection is flange plate and connection of internal is the connecting plate. Adopt high-strength bolt connection between the Stack columns, between the pillars and beams, between columns and braces. Vent tube at the bottom

\footnotetext{
${ }^{\mathrm{a}}$ Corresponding author : xuanyu@tsinghua.edu.cn
} 
of the $6 \mathrm{~m}$ Phi $610 \times 12 \mathrm{~mm}$ steel pipe, above body of the barrel is phi $406.4 * 10 \mathrm{~mm}$, all structural materials are steel 20\#, overall structure of flare stack is shown in Fig. 1.

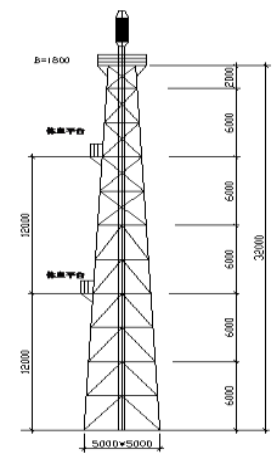

Figure 1. The overall structure of flare stack

\section{The reinforcement design of flare stack}

Flange connection structure of flare stack generally adopts a segmentation hoisting, but during the winter construction period in area of Daqing, the temperature is below $-15{ }^{\circ} \mathrm{C}$, it is windy and snowy; and there is high risk in climbing construction, high labor intensity; by combination of each sides, we determine the reasonable reinforcement and the integral hoisting of the stack, this paper conduct check calculation and analysis for the integral flare stack hoisting process. But according to stack structure analysis, the dimensions of main column are $\Phi 180 * 10$ and $\Phi 159 * 8$, adopt a $6 \mathrm{~mm}$ thick gusset plate connection between columns and beams and bracing, adopt a L63*5 connection angle between the flare and the flare barrel, considering the overall structure of the flare stack is relatively thin, in order to avoid deformation and damage during lifting operations, the overall structure of the stack must be reasonably reinforced.

\subsection{Stack overall reinforcement}

In order to enhance the overall rigidity of the stack, the integral structure of the stack set reinforcement (as shown in Fig. 2a), the channels adopt 20b U-steel, the supporting tube stack and a flare cylinder are connected as a rigid integral. Channel between the $12 \mathrm{~mm}$ thick steel plate are connected, enable it as a integral, spacing of reinforcing plate is $300 \mathrm{~mm}$, adopt a full fillet weld between the strengthen board and channel steel. U-steel are set up 3 lines in total, the first line is located at position which is $3.5 \mathrm{~m}$ from the top platform. The second is located at position which is $15.5 \mathrm{~m}$ from the the top platform. And the third is located at position which is $27.5 \mathrm{~m}$ from the top platform.

\subsection{Main lifting ear reinforcement}

The flare stack adopts integral hoisting, top platform size is $3000 \mathrm{~mm}$ and hanging ear form selection of axial lifting lugs, length is $800 \mathrm{~mm}$. In order to avoid bending moment of axial lifting ear is too large, reinforcement design on shaft type hanging ear and stack junction are shown in Fig. $2 \mathrm{~b}$.

\subsection{Sliding tail hanging ear reinforcement}

When lifting the stack as a whole, slipped tail hanging ear bear the maximum load, as shown in Fig. $2 \mathrm{c}$, adopt a $24 \mathrm{~mm}$ thick steel plate as slipped tail hanging ears and set reinforcing ring and stiffener on both sides, to improve the bearing capacity of lifting lug. 


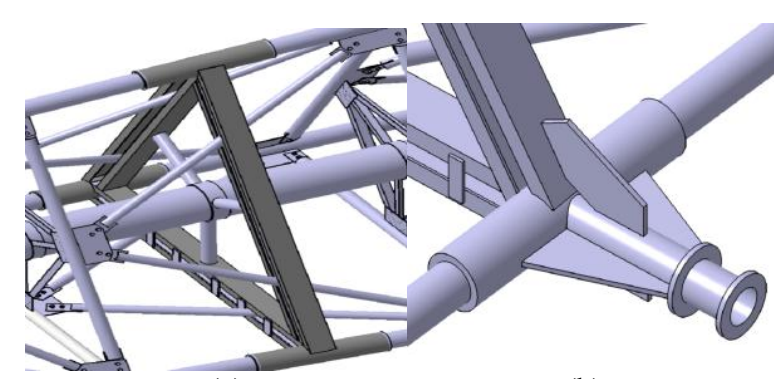

(a)

(b)

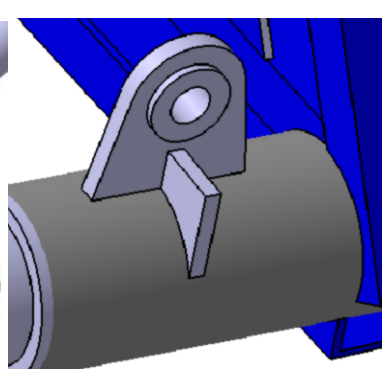

(c)

Figure 2. Figure of reinforcements. (a) is overall reinforcement of flare stack, (b) is.reinforcement of main lug and (c) is.reinforcement of sliding tail

\section{Check of the flare stack by calculation and analysis of finite element method}

\subsection{Flare stack CATIA finite-element-analysis model}

In calculation integration platform of CATIA 3D design and computer aided analysis, we build a $100 \%$ solid 3D flare stack model (Fig. 3a), and adopt CATIA self-equipped tetrahedral adaptive nonlinear mesh technology to conduct the grid division of the integral model, and conduct local mesh refinement at high stress parts to improve the accuracy of calculations. The mesh model are shown in Fig. 3b.

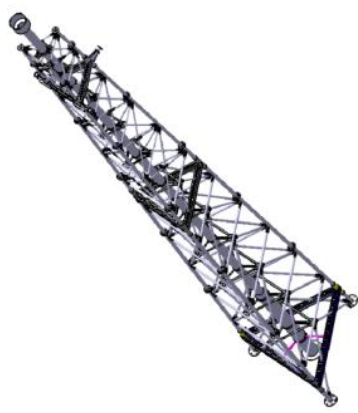

(a)

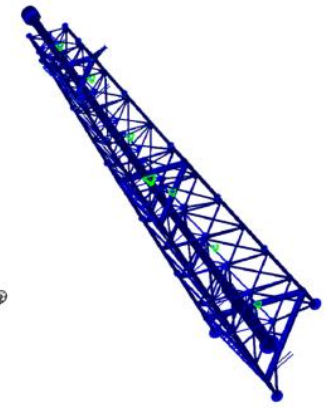

(b)

Figure 3. Model of flare stack. (a) is the 3D model of stack and (b).is integral mesh of stack

\subsection{Checking results of flare weight, center of gravity and moment of inertia}

After calculation model was established, we check the mechanical properties of the three-dimensional model of the flare stack in the CATIA software, the evaluation and analysis of the calculated total weight, center of gravity location coordinates and volumes of quality parameter data are shown in Fig. 7: 


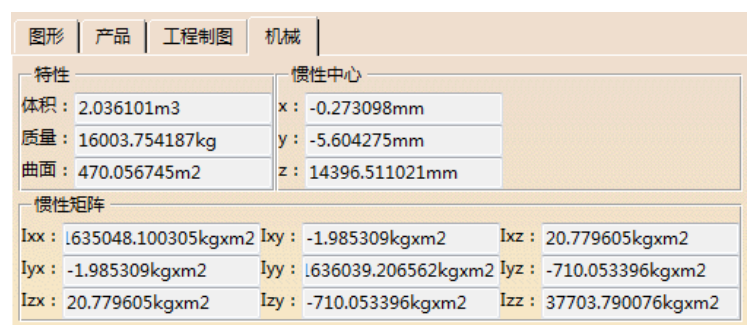

Figure 4. The overall mechanical properties of flare stack

\subsection{Finite element method for strength and deflection analysis}

Analyze the stress condition in the process of flare stack lifting in the two extreme positions, one is the flare stack in horizontal state, the automobile crane and crawler crane wire rope in accordance with the flare stack bear a flare stack weight, then lifting lugs, steel wire rope load is not large, but the flare stack itself is placed horizontally, which is under the bending moment of gravity, the the maximum of bending moment exist at the middle of the flare stack, so we check the strength and stability of flare stack; the second is that the flare stack, all the weight of the flare stack is bear on the upper lifting lug position,. At this time, the lifting lug and flare stack body near the lifting lug bear greater stress, we need to focus on the location check, the specific strength and deflection check and analysis are as follows:

\subsubsection{Flare level state analysis calculation}

\section{(1) Stress calculation}

In horizontal position, both ends of the steel wire rope is vertically upward and the upper end of the steel wire rope is set to constraint. Calculation of the Von Mises stress are shown in Fig. 8. Overall structure stress level is very low, in the order of $10 \sim 40 \mathrm{MPa}$, it is far less than the material yield strength value which is $240 \mathrm{MPa}$, so overall stress of structure in horizontal position is minor and satisfy the safety requirements.

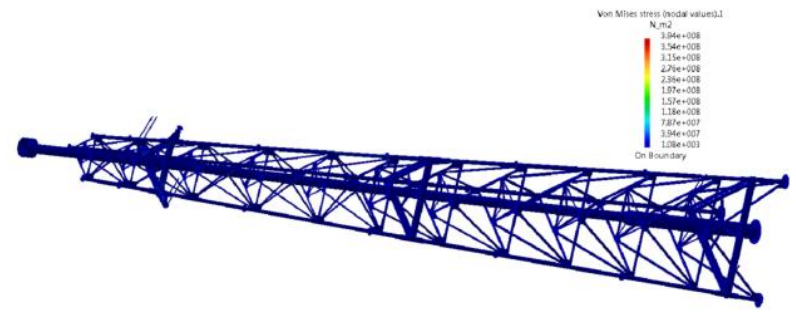

Figure 5. The overall stress calculation results

(2) Inspection and handling of dangerous points

Force monitoring of main column flange bolts shows (as shown in Fig. 6), in the horizontal position the 2,3,4level flange bolt of the upper part of the main column bear slightly greater stress, and it is between 180-260 MPa, therefore we recommend these positions of flange should be reinforced on site (as shown in Fig. 7a below). Measuring the maximum stress of main lug and it is around 100MPa (as shown in Fig. 7b), it is less than the material yield strength values, so the lug design in horizontal lifting position is safe, and satisfy the security requirements. 


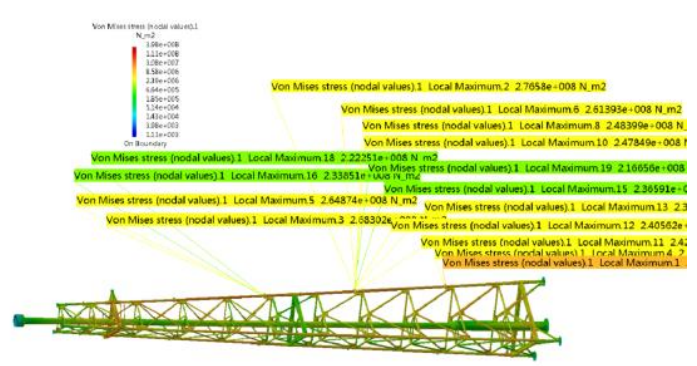

Figure 6. Inspection results of the dangerous points

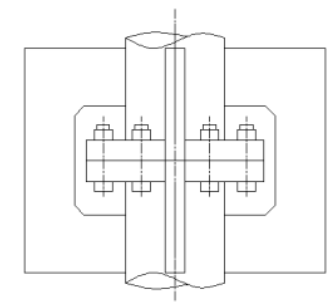

(a)

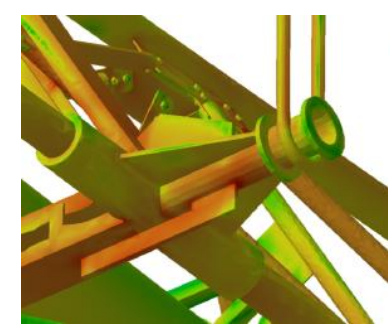

(b)

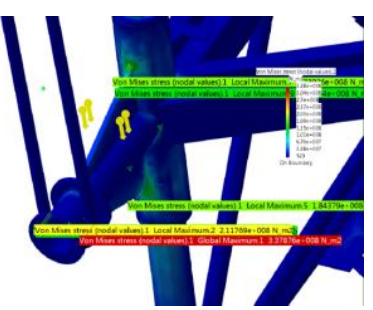

(c)

Figure 7. Partial structure and results. (a) is flange joints reinforcement structure, (b) is stress distribution of main lifting lug and (c) is graph of maximum local stress

(3) Stability analysis

Flare stack structure is in the horizontal state, when it is under the effect of gravity, will have a downward displacement, if the displacement is too large, structure in the lifting process may produce unstable failure, through the horizontal displacement, we can check whether horizontal lifting point is arranged reasonably. Fig. 8 shows displacement in the horizontal state for flare stack, maximum displacement of the middle part, is $11.1 \mathrm{~mm}$. Distance between 2 hanging points is $24 \mathrm{~m}$, maximum deflection is $[\mathrm{F}](\mathrm{m})=\mathrm{L} / 300=0.08 \mathrm{~m}>0.0111 \mathrm{~m}$, stability of visible structural satisfy safety requirements.

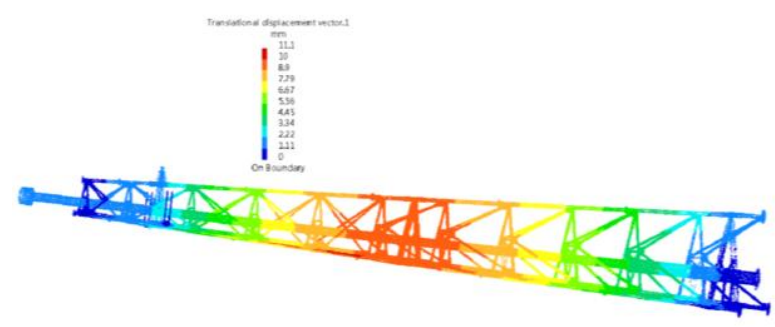

Figure 8. Calculation results of the overall displacements in horizontal position

\subsubsection{Calculation results in vertical position}

(1) Stress calculation

In vertical position, flare stack top hanging ear wire rope are vertically upward, structure is under gravity load of flare stack. Calculation of overall Von Mises stress for flare stack is shown in Fig. 9a. Overall structure stress should be minor, and is still in the order of 10 40 MPa, far less than the material yield strength value which is $240 \mathrm{MPa}$, so it satisfy the strength safety range, because the structure itself only bearing gravity load, there is no other external load. 


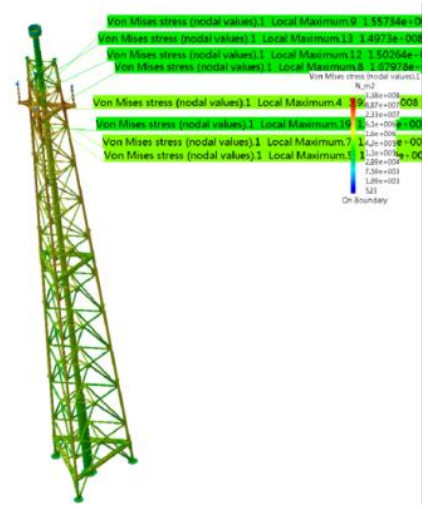

(a)

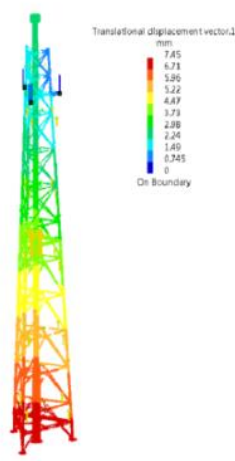

(b)

Figure 9. Results of the vertical position. (a) is overall stress cloud, (b) is overall displacement cloud

(2) Inspection and solution of dangerous points

Detection of dangerous points on the integral structure of flare stack shows, the structure withstand local maximum equivalent stress in the upper part of the flare stack where the main lifting lugs are fixed on (as shown in Fig. 7c), the maximum stress of the stack as a integral is the local stress at hanging ear reinforcing plate (value is $160 \mathrm{MPa}$ ), which is less than the material yield strength values. Therefore overall structure in the vertical lifting position is safe.

(3) Stability analysis

Calculation of overall displacement for flare stack shows (as shown in Fig. 9b), in the vertical position, the flare stack structure bear no external load, it only bear the gravity load, the displacement size is calculated, the maximum value of structure displacement is $7.45 \mathrm{~mm}$, they are located at the bottom of the flare stack, and are conformed to the requirements of the maximum deformation so the results satisfy the safety conditions.

\section{On site lifting implementation}

Refer to analyzing and checking calculation results by CATIA finite element method, and according to the reinforcement program guidance, we complete the flare stack's overall reinforcement, lug reinforcement, column flange reinforcement on site (as shown in Fig. 10a,b). On December 20th, 2015, in Zhongqiqianlin Station Risk Management Project, after 1 hour of lifting operation, the flare stack integral hoisting operation was finished completely and successfully (as shown in Fig. 10c).

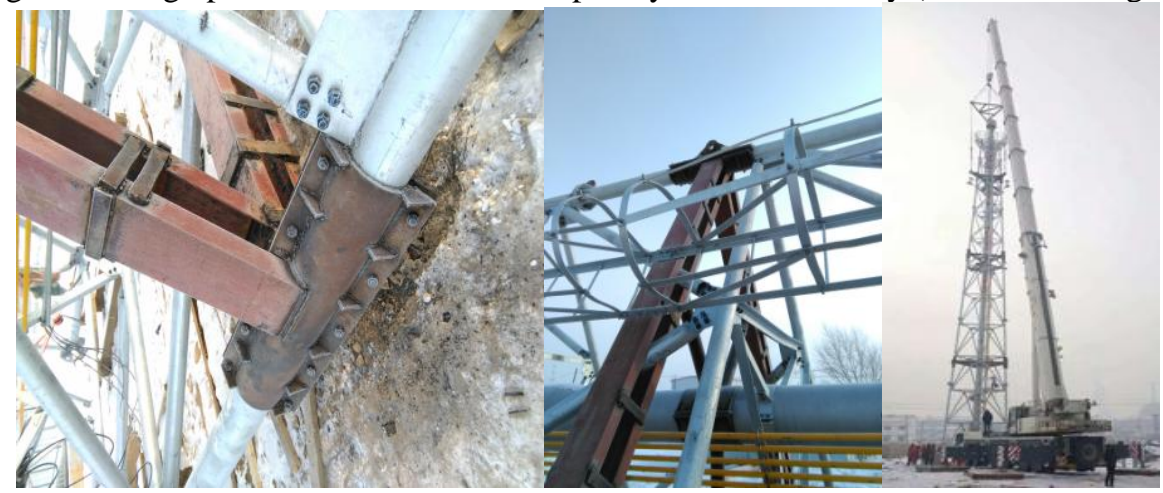

Figure 10. On site lifting photos. (a) is overall reinforcement, (b) is lifting lug and column flange reinforcement, and (c) is completion of the overall lifting 


\section{Conclusions}

(1) Because the flare stack is frivolous as a integral, we propose bold and novel innovation methods in reinforced engineering on lug reinforcement, column flange reinforcement for overall reinforcement, to ensure the flare integral hoisting stack of strength and stability better satisfy the safety requirements and ensure the hoisting operation of flare stack integral could be completed successfully.

(2) This paper explores the flange connection structure of flare stack of integral hoisting technology, saving hours of work, decreasing security risks, solving difficulties in winter construction of aerial parts assembly and segmental hoisting operation, lay a solid foundation for promotion of this hoisting method.

(3) Through the integral hoisting finite element checking calculation, we are more familiar with application of computer aided design (CAD) and master the computer aided analysis (CAE) by finite element checking calculation method and their application in this kind of flange connecting structure in flare hoisting process. We further promote hoisting technology progress for our company, and by actual lifting work we verify that the finite element strength check calculation results are accurate, fast, safe and reliable.

\section{References}

1. SH/T 3029-2014. Petrochemical exhaust tube and the flare stack design specification [M], Beijing: Ministry of Industry and Information Technology of the People's Republic of China, 2014.

2. Xuanyu Sheng, Shouqin Tang. Finite-element-analysis of the CATIA: commands and the examples[M], Beijing: Mechanical Industry Press, 2005

3. Yeluo Wang. Hoisting of large equipment management of [J]. China High-Tech Enterprises, 2010, Volume 21: 131-132. 